\title{
Perceived Safety and Driving Confidence on UK Motorways
}

\author{
Willy Hanugrah Gusti ${ }^{* *}$, Nicola Christie ${ }^{2}$
}

\author{
${ }^{1}$ University College London \\ ${ }^{2}$ University College London \\ *Corresponding author. Email: willy.gusti.20@ucl.ac.uk
}

\begin{abstract}
UK motorways are well known for their safety to the motorists, but data showed that they are not on track for Global Vision Zero on road safety. This discrepancy calls for further investigation on the safety perception that motorists have towards UK motorways. This research study seeks to find the main factors influencing UK motorways' perceived safety and driving confidence. Perceived safety is a feeling when a motorist feels safe and does not worry about unsafe circumstances on the motorway. Alternatively, driving confidence correlates to enjoying driving without being nervous and making errors. There are fourteen independent variables gathered from relevant studies which have a possible impact on safety and confidence. Online close-ended questionnaires were given to 225 motorists who have driven on UK motorways by using a convenience sampling approach. After recoded data, reliability tests, chi-square tests, and binary logistic regression analysis were conducted. A simple thematic analysis about comments related to motorways was also performed. The results from this sampling group showed that motorists who perceived UK motorways as safe were those males in the 17-35 age group holding their driving license for more than five years. Speed cameras, glare from other drivers' headlights, and HGV presence on motorways were the main factors influencing perceived safety. Then again, motorists who felt very confident driving on UK motorists were only males. This confidence was affected due to police presence and road lighting. Therefore, motorway operators need to focus on these influential factors to provide safe motorways for everyone.
\end{abstract}

Keywords: Perceived safety, driving confidence, UK motorways

\section{INTRODUCTION}

One of the safest motorways in the world is located in the United Kingdom. In 2020, the UK had 247,500 miles of road with the majority of $77 \%$ in England, and the rests are in Scotland (15\%) and Wales (8\%), respectively. Although most of these roads are managed by the local authority, the majority in each country are centrally managed by Highways England, Transport Scotland, and the Welsh Government [1]. These motorways play an essential role for the UK economy, from enabling accessible logistics distribution centers to helping small towns expands.

The last three years from 2017-2019 showed that fatalities rose by $8 \%$ in 2018 but slightly fell by $2 \%$ in 2019. For KSI, the fluctuation indicated more or less theexact percentages [2]. These percentages do not illustrate that KSI on UK motorways will halve by 2025 as Highways England aspired, let alone achieve Global Vision Zero for road safety [3].

Although motorways have worked quite well, there are some areas for improvement related to journey times' reliability and information delivery management. Incident management and roadworks affect the reliability of journey times. Therefore, major incidents must be established to minimize loss time for road users. Regarding information, motorways operator's website sometimes is not up to date to the current situation, making it confusing for logistic operators to monitor their fleet. Fortunately, after being involved in the research about perceptions of safety, drivers have changed their mindset to consider safety the highest factor in evaluating motorways performance [4].

When motorways are compared to rural and urban roads, their fatalities proportion is only $6 \%$. 
This means that motorways are safe enough, but the critical question is sometimes left out: how do we define 'feeling safe'? The fact that 'feeling safe' is not merely a feeling but a lack of harmful involvement in a risky situation [4]. Moreover, the 'safe system' approach to road safety helps map unsafety feelings from safe people to safe vehicles. Learning from recent qualitative research conducted in perceived safety on Strategic Road Network, further investigation is needed to represent the population quantitatively. This research analyses the main factors influencing safety and confidence while driving on UK motorways and the implication of these results towards delivering motorways with an expected level of service that ensure safety and driving confidence for the motorists.

\subsection{Research Objectives}

This research aims to assess UK motorways' perceived safety and driving confidence and investigate the main factors influencing these perceptions. The objectives of this research are to:

1. Distribute online questionnaires to understand how roadusers perceive motorways regarding their safety and driving confidence.

2. Analyze the data using the chi-square test and binary logisticregression model to assess perceived safety and confidencewhilst driving by correlating it to chosen independent variables based on literature review.

This research study aims to fill the gaps by quantitatively showing the main factors influencing perceived safety and confidence while driving on UK motorways. The differences between perceived safety and driving confidence within gender, age group, or educational qualification may become interesting findings. Certain gender might feel safer driving on UK motorways than the other. Moreover, the result also intends to describe the implication of delivering safer UK motorways. This research also analyzes the understanding of additional support while driving on motorways.

\section{METHOD}

Mixed-method research was chosen for this study to increase the likelihood of unforeseen outcomes from the research. Distributing online questionnaires consisting of Likert scale, multiple-choice, and freetext comments combined the strengths from quantitative and qualitative methods, simultaneously offset the weaknesses of just using one method. The qualitative method in this study explained further the view from participants towards the study object, even though general findings were concluded from the quantitative method. The combination of quantitative and qualitative research complemented one another, especially when the quantitative method found surprising results [5].

Embedded design is the most suitable mixedmethods design illustrating this study. The primary priority approach in this research study was the quantitative method by drawing findings from a sample. But then, a qualitativemethod was embedded to complete the conclusions [6]. The quantitative method is important to generalize the population to a sample in which illustrates how motorists feel on UK motorways in terms of safety and driving confidence. Robust data was drawn with less probability of bias through quantitative analysis. On the other hand, the qualitative method as the embedment gave feedback on how UK motorways service level should be for motorists. The weakness was probably bias that may be made since it only came from an individual point of view.

\subsection{Questionnaire Design}

Online self-completion questionnaires were used in this study because of its internal and measurement validity. There were two distinctive stages for questionnaire design in this study: the piloting stage and the data collection stage. The piloting stage was needed to confirm the understanding of the participants towards online questionnaires. Five motorists took part in this stage either in-person or online through Opinio Survey Software, officially provided by University College London. Participants were asked to complete the preliminary online questionnaires themselves with an additionaltextbox where they may put any comment if the question was not easily understood. There were 34 questions in total for this piloting stage. Likert scale from Strongly Disagree to Strongly Agree used to measure qualitative data, in this case, feeling of safety and driving confidence on UK motorways, to become ordinal variables.

After the piloting stage was done, questionnaires were adjusted based on feedback from participants, especially for a question that was difficult to understand. The adjustments could be made to revise the wording, scale, or even to add a picture to help explain the question. Then, final online questionnaires were distributed to 225 participants. 


\subsection{Quantitative Method}

There are three quantitative methods for this research, which are reliability test for internal consistency, chi-square test for association, and binary logistic regression. As this research study sought to define how motorists perceive safety and confidence while driving on motorways, logistic regression was a suitable model. This research study followed the Backward Stepwise Likelihood Ratio method performed by SPSS. The method firstly used all variables in the null modelthen insignificant variables were removed until the last step. Only significant variables were shown in the final model.

\subsection{Qualitative Method}

Although most parts of the methodology in this research study used quantitative methods, the qualitative method also played a significant role. There was only one section in the questionnaire that could be analyzed qualitatively using thematic analysis. From the name itself, thematic analysis began by reading and coding the data so that analysts could group topics from the data to conclude the themes appropriate for the research question.

\section{RESULT}

\subsection{Binary Logistic Regression Result}

Two models were analyzed using Binary Logistic Regression by SPSS software. The preferred method was Backward Stepwise so that all independent variables, demographics, and driving experiences could be included. At first, the Backward Stepwise method included all variables, then eliminated insignificant variables in each step until significant variables were obtained. To perform this logistic regression, dependent variables were recoded into binary scale.

\subsubsection{Perceived Safety Model}

The first analysis on perceived safety model was to compare Block 0 (null model without independent variables) with Block 1 (full model). There was an improvement in the full model by including all the variables. The overall percentage went up from $81.8 \%$ to $83.6 \%$ in the full model. This means that the independent variables help enhancing the perceived safety model.

Table 1 shows results from the last step of the perceived safety model. There were six statistically significant variables that have p-values less than 0.05 , denoted by $*$ in the last column. This means that there were associations between each of the six variables with perceived safety. The coefficient of each variable in the model was listed under column B. Nevertheless, column B cannot be used to interpret the significant effects. The interpretation can only be made by using odd ratios from column $\operatorname{Exp}(B)$. For instance, the odds ratio of 3.125 for gender (1) means that odds of males perceiving UK motorways as very safe were 3.125 times the odds for females. Age and driving license were significant altogether. The interpretation of odds ratios for these variables was like gender. Two other significant variables were HGV, Speed Cameras, and Glare. Traffic Accident History, No Hard Shoulder, and Police Presence were the insignificant variables from Step 12 Perceived Safety Model.

\subsubsection{Driving Confidence Model}

The classification table of the second model showed no improvement by including independent variables. Percentage corrects stayed the same at $83.2 \%$ for the driving confidence model.

From Table 2, the backward stepwise binary logistic regression finished on step 18 with only three categorical variables on the driving confidence model. Gender, unlit motorway, and police presence were the significant variables. The odds of a male motorist being confident while driving on UK motorways were 2.461 times the odds of the female being confident. Only unlit motorways and police presence affected driving confidence on UK motorways. 
Table 1. Variables in the Equation on Step 12 Perceived Safety Model

\begin{tabular}{|c|c|c|c|c|c|}
\hline Variable & B & SE. & $\operatorname{Exp}(B)$ & Sig. & $\mathrm{p}<0.05$ \\
\hline Age_Recoded & & & & 0.014 & * \\
\hline Age_Recoded(1) & 1.313 & 0.558 & 3.718 & 0.019 & * \\
\hline Age_Recoded(2) & 1.556 & 0.679 & 4.741 & 0.022 & * \\
\hline Genōer_Recoded(1) & 1.139 & 0.440 & 3.125 & 0.010 & * \\
\hline $\begin{array}{l}\text { How many years have you held your } \\
\text { driving license? }\end{array}$ & & & & 0.003 & * \\
\hline $\begin{array}{l}\text { How many years have you held your } \\
\text { driving license? (1) }\end{array}$ & -2.935 & 0.916 & 0.053 & 0.001 & * \\
\hline $\begin{array}{l}\text { How many years have you held your } \\
\text { driving license? (2) }\end{array}$ & -1.778 & 0.808 & 0.169 & 0.028 & * \\
\hline $\begin{array}{l}\text { Have you ever been involved in a traffic } \\
\text { accident in the past three years on any } \\
\text { road? (1) }\end{array}$ & -19.275 & 8724.742 & 0.000 & 0.998 & \\
\hline $\begin{array}{l}\text { I feel unsafe when there are so many } \\
\text { Heavy Good Vehicles/Lorries on the } \\
\text { motorway. }\end{array}$ & & & & 0.075 & \\
\hline I feel unsafe when there are so many & & & & & \\
\hline $\begin{array}{l}\text { Heavy Good Vehicles/Lorries on the } \\
\text { motorway(1) }\end{array}$ & -0.027 & 0.490 & 0.973 & 0.955 & \\
\hline $\begin{array}{l}\text { I feel unsafe when there are so many } \\
\text { Heavy Good Vehicles/Lorries on the } \\
\text { motorway(2) }\end{array}$ & 2.037 & 0.908 & 7.666 & 0.025 & * \\
\hline $\begin{array}{l}\text { I feel unsafe when the hard shoulder is } \\
\text { being used for traffic. }\end{array}$ & & & & 0.062 & \\
\hline $\begin{array}{l}\text { I feel unsafe when the hard shoulder is } \\
\text { being used for traffic. (1) }\end{array}$ & 1.025 & 0.605 & 2.788 & 0.090 & \\
\hline $\begin{array}{l}\text { I feel unsafe when the hard shoulder is } \\
\text { being used for traffic. (2) }\end{array}$ & 1.268 & 0.663 & 3.554 & 0.056 & \\
\hline $\begin{array}{l}\text { Police presence on motorways makes } \\
\text { me feel safer. }\end{array}$ & & & & 0.071 & \\
\hline $\begin{array}{l}\text { Police presence on motorways makes } \\
\text { me feel safer. (1) }\end{array}$ & 1.804 & 0.930 & 6.076 & 0.052 & \\
\hline $\begin{array}{l}\text { Police presence on motorways makes } \\
\text { me feel safer.(2) }\end{array}$ & -0.226 & 0.484 & 0.798 & 0.641 & \\
\hline $\begin{array}{l}\text { I feel safe on the motorway when there } \\
\text { are speed cameras. }\end{array}$ & & & & 0.101 & \\
\hline $\begin{array}{l}\text { I feel safe on the motorway when there } \\
\text { are speed cameras.(1) }\end{array}$ & -0.823 & 0.690 & 0.439 & 0.233 & \\
\hline $\begin{array}{l}\text { I feel safe on the motorway when there } \\
\text { are speed cameras. (2) }\end{array}$ & -1.172 & 0.548 & 0.310 & 0.033 & * \\
\hline $\begin{array}{l}\text { I find the glare from other driver's } \\
\text { headlights make me feel unsafe driving } \\
\text { on the motorway in the dark. } \\
\text { I find the glare from other driver's }\end{array}$ & & & & 0.099 & \\
\hline $\begin{array}{l}\text { headlights makes me feel unsafe driving } \\
\text { on the motorway in the dark. (1) } \\
\text { I find the glare from other driver's }\end{array}$ & 0.361 & 0.584 & 1.435 & 0.536 & \\
\hline $\begin{array}{l}\text { headlights makes me feel unsafe driving } \\
\text { on the motorway in the dark.(2) }\end{array}$ & 1.227 & 0.571 & 3.410 & 0.032 & * \\
\hline Constant & 19.289 & 8724.742 & 238239180.916 & 0.998 & \\
\hline
\end{tabular}


Table 2. Variables in the Equation on Step 18 Driving Confidence Model

\begin{tabular}{|c|c|c|c|c|c|}
\hline Variable & B & S.E. & $\operatorname{Exp}(B)$ & Sig. & $p<0.05$ \\
\hline Gender_Recoded(1) & 0.901 & 0.384 & 2.461 & 0.019 & * \\
\hline $\begin{array}{l}\text { I feel unsafe driving on the motorway at night } \\
\text { when it is unlit. }\end{array}$ & & & & 0.011 & * \\
\hline $\begin{array}{l}\text { I feel unsafe driving on the motorway at night } \\
\text { when it is unlit.(1) }\end{array}$ & 1.484 & 0.506 & 4.410 & 0.003 & * \\
\hline $\begin{array}{l}\text { I feel unsafe driving on the motorway at night } \\
\text { when it is unlit. (2) }\end{array}$ & 0.721 & 0.518 & 2.057 & 0.164 & \\
\hline $\begin{array}{l}\text { Police presence on motorways makes me } \\
\text { feel safer. }\end{array}$ & & & & 0.046 & * \\
\hline $\begin{array}{l}\text { Police presence on motorways makes me } \\
\text { feel safer.(1) }\end{array}$ & -0.042 & 0.599 & 0.958 & 0.944 & \\
\hline $\begin{array}{l}\text { Police presence on motorways makes me } \\
\text { feel safer.(2) }\end{array}$ & -0.971 & 0.435 & 0.379 & 0.026 & * \\
\hline Constant & 1.006 & 0.398 & 2.734 & 0.011 & * \\
\hline
\end{tabular}

\subsection{Thematic Analysis Result}

Based on the literature review, fourteen independent variables might influence perceived safety and driving confidence on UK motorways. These variables were analyzed quantitatively with the chi-square test and binary logistic regression model. The last step was to find these variables or topics on free-text comments available at the end of the online questionnaire. Only five topics were not discussed in the comments: Roadside Traffic Sign, Safe Area, Overhead Signs, Speed Cameras, and Service Stations. Interestingly, other topics were brought up, from smart motorways to navigation aid. Figure 1 illustrates how the topics were combined after thematic analysis.

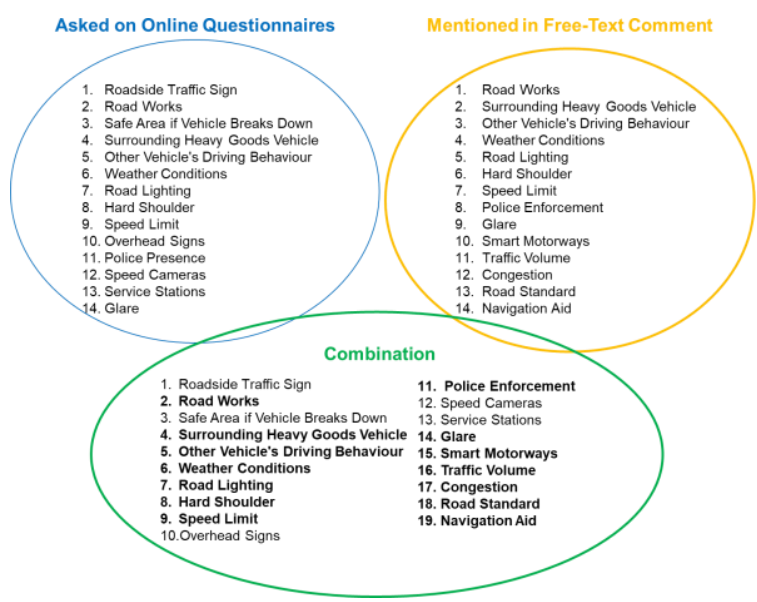

Figure 1 Visual Summary of Thematic Analysis

\section{DISCUSSION}

Binary logistic regression indicated that perceived safety on UK motorways was highly influenced by age, gender, years holding the driving license, HGV, speed cameras, and glare. In other words, being male in the 17-35 age group with more than five years driving license made motorists generally feel safe driving on UK motorways.

However, HGV, speed cameras, and glare from other vehicle's headlights might affect their safety perception. As mentioned in the study by [4] and qualitative analysis in this study, HGVs had a big impact towards unsafe feelings. The second model of driving confidence showed that only gender, unlit motorway, and police presence had the biggest influences. UK motorways did not yet provide confidence for females, especially ifthere was a lack of police and no lighting installed. The phenomenon of improved driving behavior when police are spotted by the motorists was noted in another study [7].

There were five new topics mentioned in the thematic analysis. Traffic volume, congestion, road standard, and navigation aid were not in high demand, but smart motorways were worth more to look at. Major issues with smart motorways were hard shoulder removal and non-compliance towards the signs [4]. This was evident that further driving education about smart motorways was needed to ensure the safety and driving confidence of the motorists. 
Although care has been taken to produce satisfying results, the quantitative method presented may not be asrepresentative as the household survey. The whole population of motorists driving on UK motorways mightnot be reached. With limited budget and time, online questionnaires were chosen to be the best option to gather samples for this perceived safety and driving confidence study. Findings from quantitative and qualitative methods possibly do not produce the strongest conclusion. However, mixedmethod research is believed to be reliable in this study.

\section{STUDY LIMITATION}

This research study had successfully produced useful quantitative and qualitative results from a relatively small sample size within a limited budget and time. However, this study was not able to provide a holistic point of view of perceived safety and driving confidence on UK motorways. Sample representativeness, questionnaire validity and chosen methodology are the main limitations of this study.

Choosing a convenience sampling method for the MScresearch project was the most feasible option at the time. This non-probability sampling simply used the researcher's network to gain responses. However, the main problem with convenience sampling was its inability to represent the population of motorists on UK motorways. Even though the survey link was distributed until secondary network, the response rate was still below $60 \%$. This problem possibly happened because the link was circulated throughout Imperial College London and University College London networks, where many London residents were usually public transport users rather than drivers. If they were drivers, there were possibilities that they not have driven on motorways. Link circulation within these two campuses also explained why educational qualification data were skewed into undergraduate and postgraduate degrees. There was another effort to approach coach drivers to obtain wider views, but it was unsuccessful due to rejection.

Next, the online questionnaire was the main data collection tool which had some major drawbacks. Bias thought from each participant was more likely to be the problem because the survey was unsupervised. If participants were unsure about some questions, they could not seek clarification.

Finally, mixed methods of quantitative and qualitative analysis might not be the best way to approach the research questions. The first two research questions were answered from quantitative analysis, but the last question combined both methods. Nevertheless, the source of qualitative analysis was only from one free-text column where the question was very general. Most of the answers were able to complement findings from quantitative analysis, but few responses were not relevant. It was also up to the researcher's point of view on how to understand the answers.

\section{ACKNOWLEDGMENTS}

The authors would like to acknowledge Deirdre O'Reilly from Highways England and Dr. Sarah O'Toole, who has been very helpful in this research process. We also thank the participants involved by filling in the online questionnaires.

\section{REFERENCES}

[1] Department for Transport, Road Lengths in Great Britain 2020, Online: Department for Transport, 2021. Available at: https://assets.publishing.service.gov.uk/govern ment/uploads/system/uploads/attachment_data/f ile/957882/road-lengths-in-great-britain2020.pdf (Accessed: 28 July 2021).

[2] Department for Transport, STATS19 Road Accidents and Safety Statistics. Online: Department for Transport, 2020. Available at: https://roadtraffic.dft.gov.uk/customdownloads/road-accidents/reports/54be3530e16f- 4043-ada7-572ddb2579f5 (Accessed: 28 July2021).

[3] Highways England, Delivery plan 2020-2025. Guildford: Highways England, 2020. Available at:

https://highwaysengland.co.uk/5yearDeliverypl an (Accessed: 28 July 2021).

[4] Posner, R., Christmas, S., Cooper, A., Shepherd, J. \& Helman, S, Perceptions of safety: findings from focus groups. Berkshire: TRL Limited, 2020. Available at: https://trl.co.uk/uploads/trl/documents/PPR953 Perceptions-of-safety FINAL.pdf (Accessed: 20 May 2021).

[5] Bryman, A., 'Integrating quantitative and qualitative research: how is it done?', Qualitative Research, 2006, 6(1), pp. 97-113. DOI: $10.1177 / 1468794106058877$.

[6] Creswell, J. W. \& Plano Clark, V. L., Designing and conducting mixed methods research. Third International Student Edition, SAGE, 2017. 
[7] Sharp, R., Wells, H., Fernandez, K. \& Helman, S., Perceptions of compliance and enforcement on the Strategic Road Network: Focus groups and interviews (PPR954), Berkshire: TRL Limited, 2020. Available at: https://search.datacite.org/works/10.13140/rg.2. 2.3 0550.06728 (Accessed: 3 August 2021). 